\title{
Nasal Cavity and Ethmoid Sinus Cancer Pathologic Primary Tumor TNM Finding v8
}

National Cancer Institute

\section{Source}

National Cancer Institute. Nasal Cavity and Ethmoid Sinus Cancer Pathologic Primary

Tumor TNM Finding v8. NCI Thesaurus. Code C133028.

A pathologic finding about one or more characteristics of nasal cavity and ethmoid sinus cancer, following the rules of the TNM AJCC v8 classification system as they pertain to staging of the primary tumor. 